\title{
Experimental investigation of environmentally friendly drilling fluid additives (mandarin peels powder) to substitute the conventional chemicals used in water-based drilling fluid
}

\author{
Abo Taleb T. Al-Hameedi ${ }^{1}$. Husam H. Alkinani ${ }^{1}$ - Shari Dunn-Norman ${ }^{1}$ - Mustafa A. Al-Alwani ${ }^{1}$. \\ Abdullah F. Alshammari ${ }^{1}$ - Mohammed M. Alkhamis ${ }^{1}$ - Rusul A. Mutar ${ }^{2}$ - Waleed H. Al-Bazzaz ${ }^{3}$
}

Received: 19 March 2019 / Accepted: 25 June 2019 / Published online: 1 July 2019

(c) The Author(s) 2019

\begin{abstract}
The non-biodegradable additives used in controlling drilling fluid properties cause harm to the environment and personal safety. Thus, there is a need for alternative drilling fluid additives to reduce the amount of non-biodegradable waste disposed to the environment. This work investigates the potential of using mandarin peels powder (MPP), a food waste product, as a new environmentally friendly drilling fluid additive. A complete set of tests were conducted to recognize the impact of MPP on the drilling fluid properties. The results of MPP were compared to low viscosity polyanionic cellulose (PAC-LV), commonly used chemical additive for the drilling fluid. The results showed that MPP reduced the alkalinity by $20-32 \%$ and modified the rheological properties (plastic viscosity, yield point, and gel strength) of the drilling fluid. The fluid loss decreased by $44-68 \%$ at concentrations of MPP as less as $1-4 \%$, and filter cake was enhanced as well when comparing to the reference mud. In addition, MPP had a negligible to minor impact on mud weight, and this effect was resulted due to foaming issues. Other properties such as salinity, calcium content, and resistivity were negligibly affected by MPP. This makes MPP an effective material to be used as $\mathrm{pH}$ reducer, a viscosity modifier, and an excellent fluid loss agent. This work also provides a practical guide for minimizing the cost of the drilling fluid through economic, environmental, and safety considerations, by comparing MPP with PAC-LV.
\end{abstract}

Keywords Eco-friendly additives $\cdot$ Drilling fluid $\cdot$ Mandarin peels powder (MPP)

\section{Introduction}

Drilling fluid is a complex system that consists of liquids, solids, and chemicals. The base of the drilling fluid can be water, oil, or in some cases both. Several types of chemicals and polymers are added to the base fluid to meet the required properties of the drilling fluid such as viscosity, density, fluid loss control, and chemical composition. The factors that guide the selection of base fluid and the additives are

Abo Taleb T. Al-Hameedi

ata2q3@mst.edu

Husam H. Alkinani

hhappf@mst.edu

1 Missouri University of Science and Technology, Rolla, MO, USA

2 Ministry of Communications and Technology, Baghdad, Iraq

3 Kuwait Institute for Scientific Research, Kuwait City, Kuwait complex and well discussed (Gray et al. 1980; Okorie 2009). Environmental considerations led to an increase in the interest of using water-based drilling fluid over oil-based drilling fluid due to the high toxicity of the latter, especially in environmentally sensitive locations. In addition, most of the conventional chemical additives fall under the category of non-biodegradable materials and pose several dangers when released to the environment. These additives including but not limited to; potassium chloride, potassium sulfate, polyamine, and fluid loss additives, etc., have an overall negative environmental impact (Amanullash 2007). Thus, there is a demand for new environmentally friendly additives that can help to control the drilling fluid properties and improve their effectiveness with the least effects on the environment.

Today, there is an increase in the global concerns for the protection of the environment from the detrimental effect of chemical and non-biodegradable materials. These concerns drive the industry toward drilling fluid optimization techniques to develop safer and environmentally friendly 
formulations. Recent research efforts have examined the applicability of food waste as drilling fluid additives (AlHameedi et al. 2019a).

One example of utilizing food waste products was conducted by Al-Hameedi et al. (2019b) which showed that potato peels powder (PPP) reduced the fluid loss, decreased the yield point and increased the plastic viscosity. Iranwan et al. (2009) tested corncob and sugarcane as environmentally friendly viscosifying agents. The results of this study showed an improvement in plastic viscosity but a reduction in the yield point and gel strength at concentrations from 6 to 10 part per billion (ppb). Okon et al. (2014) revealed in their study that a concentration of $20 \mathrm{ppb}$ rice husk was able to reduce the drilling fluid loss by $65 \%$ when compared to $10 \mathrm{ppb}$ of carboxymethyl cellulose (CMC). On the other hand, the high concentration of rice husk might result in an undesirable effect on the plastic viscosity and pose a risk to delicate measurement while drilling (MWD) tools, which points out the importance of optimizing the concentration of rice husk. Other materials were also examined to investigate their ability to enhance the rheological and filtration properties of water-based drilling fluid. These materials are cellulose from corncob (Nmegbu and Bekee 2014), cashew and mango leaves extracts (Omotioma et al. 2014), and potato starch extracted from potato tubers (Nyeche et al. 2015). The cellulose from corncob was efficient in reducing fluid loss compared to polyanionic cellulose (PAC), and the cashew and mango leaves extracts improved the rheological properties of the drilling fluid, while the potato starch extracted from potato tubers had negative impacts on the rheological and filtration characteristics. Adebowale and Raji (2015) examined the use of banana peel ash (BPA) as a substitute additive for sodium hydroxide $(\mathrm{NaOH})$ to $\mathrm{pH}$ and corrosion control. The study showed a significant enhancement in $\mathrm{pH}$ because of adding BPA. However, comparison of improvement from the same concentration of BPA and $\mathrm{NaOH}$ showed an improvement in pH by 12 and 14, respectively. Similarly, Iheagwara (2015) showed that banana peel exhibits an alkaline property on drilling fluid as conventional caustic soda (sodium hydroxide). PAC is a water-soluble polymer that is a cellulose derivative, produced by the chemical reaction of cellulose with carboxymethyl (anionic) groups (Balestrini et al. 2009). It is a very common additive used in the field as fluid loss control agent, and PAC properties are well known (Thomas 1982).

In this work, the interaction between water-based drilling fluid and mandarin peels powder (MPP), which is a biodegradable food waste product, was investigated. The main objective of this study is to enhance the physical and chemical properties of the drilling fluid using an alternative environmentally friendly additive. The performance of the drilling fluid in the presence of MPP was compared to that of PAC-LV to show the feasibility of applying MPP in the field.
In addition, to provide a workable guideline for minimizing the cost of the drilling fluid and reducing the amount of nonbiodegradable waste disposed to the environment.

\section{Materials and methods}

Under this section, details about the collection and preparation of the mandarin peels powder (MPP) will be discussed. Also, an evaluation of PAC-LV was used for comparison with MPP in terms of performance efficiency. In addition, the reference drilling fluid properties, as well as the conducted set of tests using different blends of MPP and PAC$\mathrm{LV}$ at different concentrations, will be presented.

\section{Collection and preparation of the mandarin peels powder (MPP)}

The raw waste mandarin peels were collected at home as shown in Fig. 1. Then, it was chopped into very small pieces to accelerate the drying process and get rid of the moisture rapidly as shown in Fig. 2. The small pieces of mandarin peels were placed in an oven at $90-95{ }^{\circ} \mathrm{C}$ $\left(195-204{ }^{\circ} \mathrm{F}\right)$ for $3 \mathrm{~h}$. After that, they were left in a dry space under ambient laboratory conditions, for 10 days as shown in Fig. 3. Finally, to guarantee a full drying process, the mandarin peels were placed in an oven again at $90-95^{\circ} \mathrm{C}\left(195-204{ }^{\circ} \mathrm{F}\right)$ until the material was entirely oxidized. Once dried, the mandarin peels were ground into a fine powder using a food processor. Sieve analysis test by using manual sieves has been applied to determine the

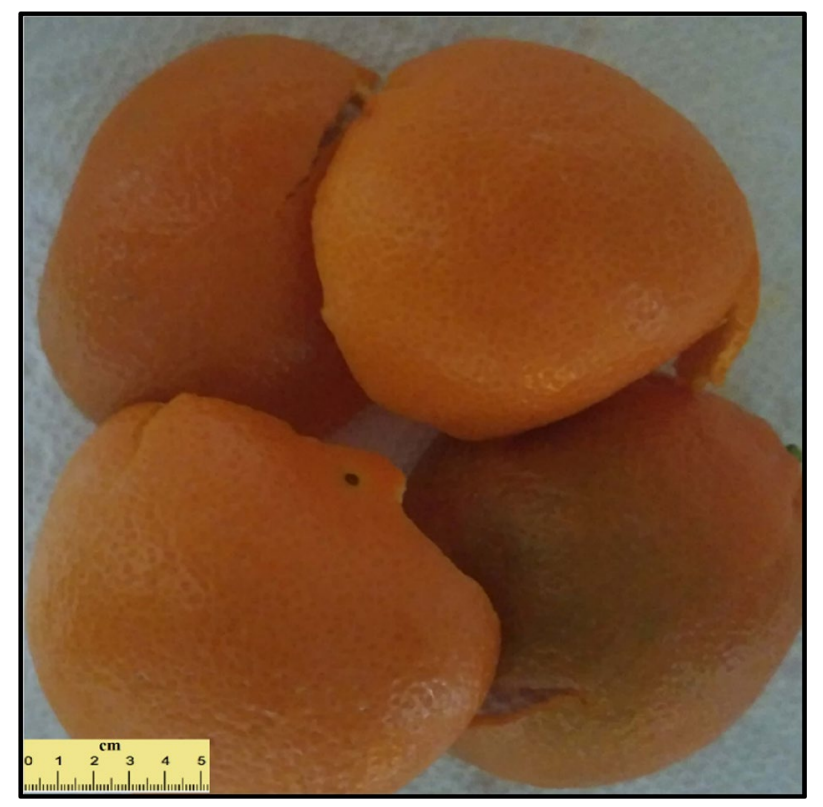

Fig. 1 The raw waste of mandarin peels 


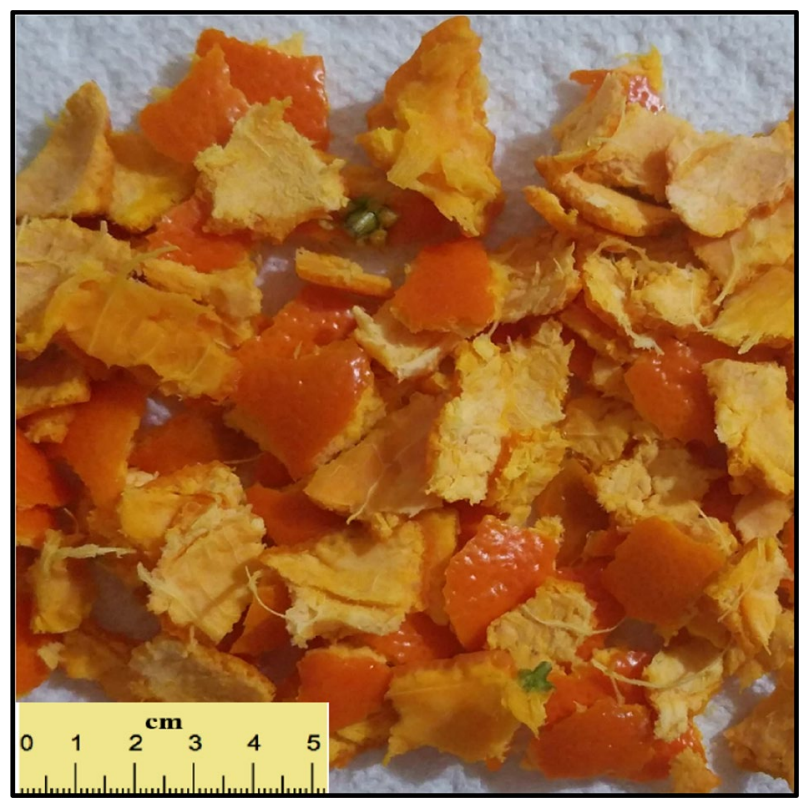

Fig. 2 Very small-chopped pieces of mandarin peels

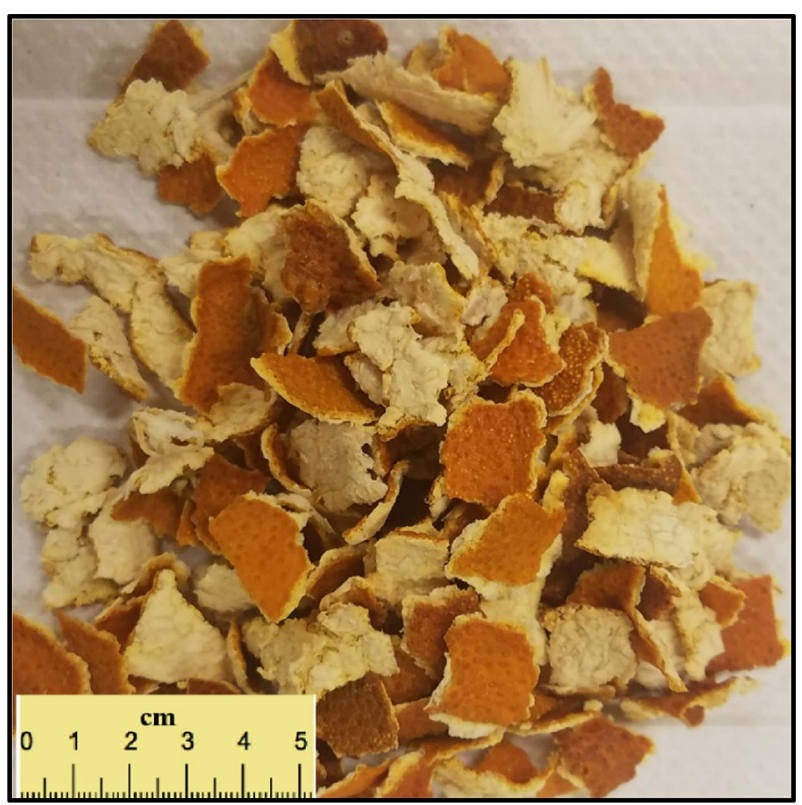

Fig. 3 The dried small pieces of mandarin peels

size of the peels powder. The test findings approximated that the MPP has a size between 210 and $250 \mu \mathrm{m}$ (70 US Mesh size-60 US Mesh size). In the same context, Figs. 4 and 5 illustrate the fine powder of the mandarin peels and the food processor, respectively, while Fig. 6 demonstrates the workflow preparation of MPP as a powder.

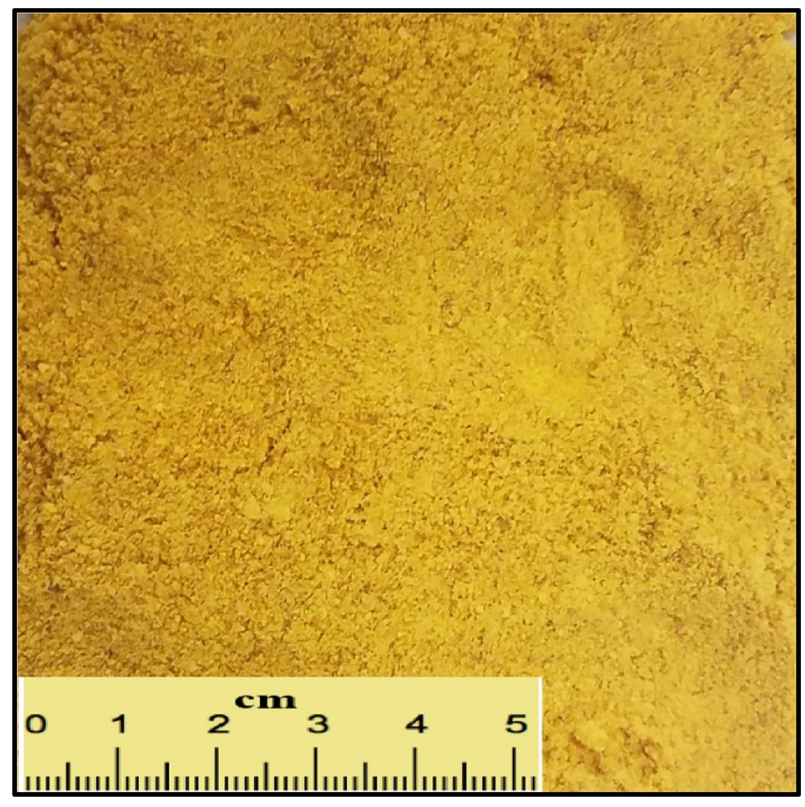

Fig. 4 Mandarin peels powder (MPP)

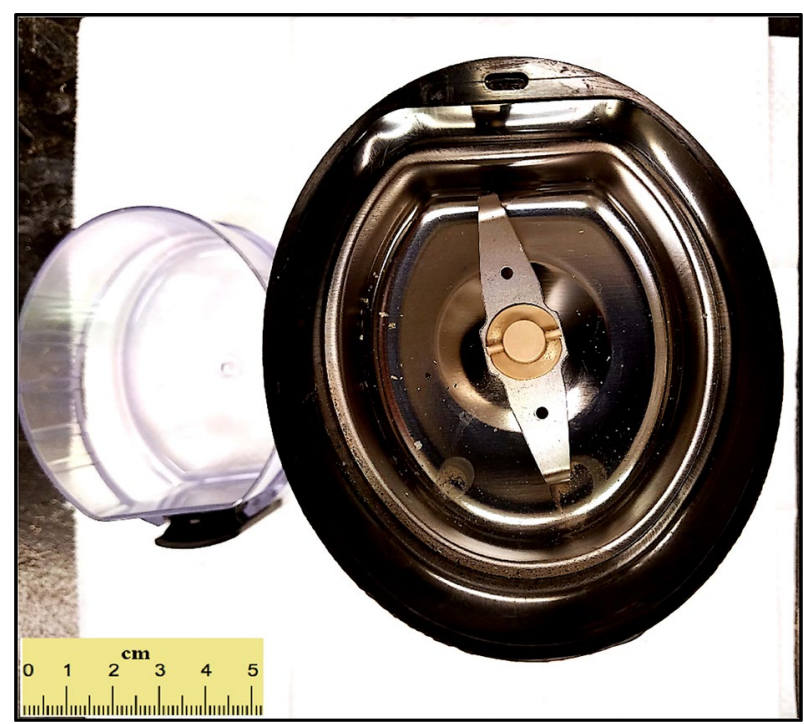

Fig. 5 The food processor

\section{Low viscosity polyanionic cellulose (PAC-LV)}

For drilling oil and gas wells, PAC-LV (shown in Fig. 7) is used as a drilling fluid additive to improve the properties of the drilling mud and provide a tangible enhancement in the mud performance. It is a high purity additive used in water-based mud, and it can be applied in freshwater drilling, brackish water, seawater drilling, and brine water-based mud systems. It has very good specifications such as easily soluble in water, having excellent properties of salt resistance, calcium and magnesium resistance, shale stability, and 
Fig. 6 The workflow of collection and preparation of the MPP
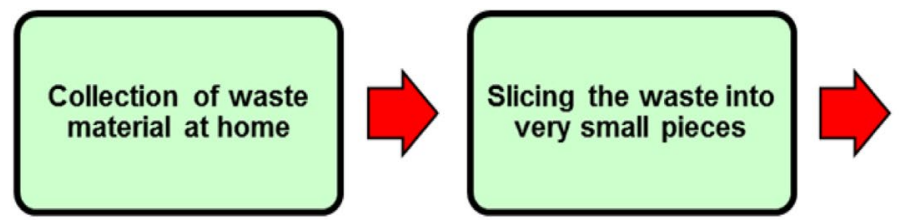

Placement in an oven at $90-95^{\circ} \mathrm{C}(195$ $204^{\circ} \mathrm{F}$ ) for three hours

Finally, it was ground into a very fine powder
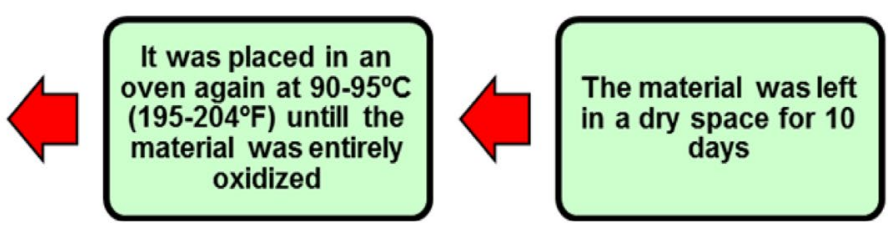

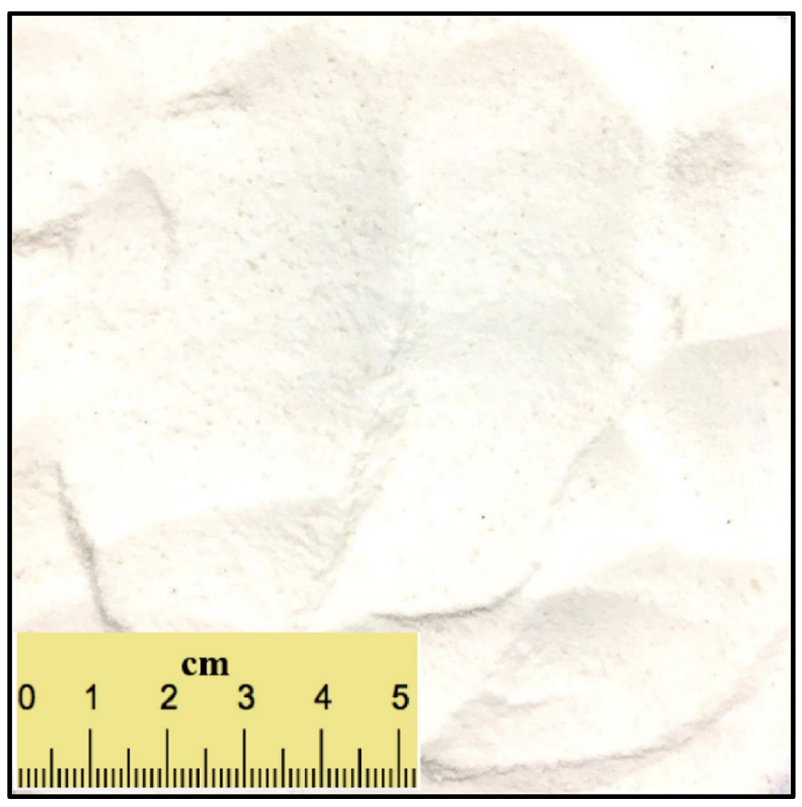

Fig. 7 PAC-LV

less productive zone damages. PAC-LV is a premium product having a higher degree of carboxymethyl substitution and contains less residual $\mathrm{NaCl}$ than technical grade carboxymethyl cellulose alone. Along with reducing filtration loss, PAC-LV can be used as a thickening agent, rheology controller, bond, stabilizer, colloid protector, and suspending agent (Halliburton 2018). Sieve analysis test by using manual sieves has also been applied to determine the size of the PAC-LV powder. The test findings approximated that the PAC-LV has a size between 105 and $125 \mu \mathrm{m}$ (140 US Mesh size-120 US Mesh size).

\section{Mud sample preparation}

"Pilot testing of drilling fluids is testing performed on proportionately small-scale samples. It is an essential part of

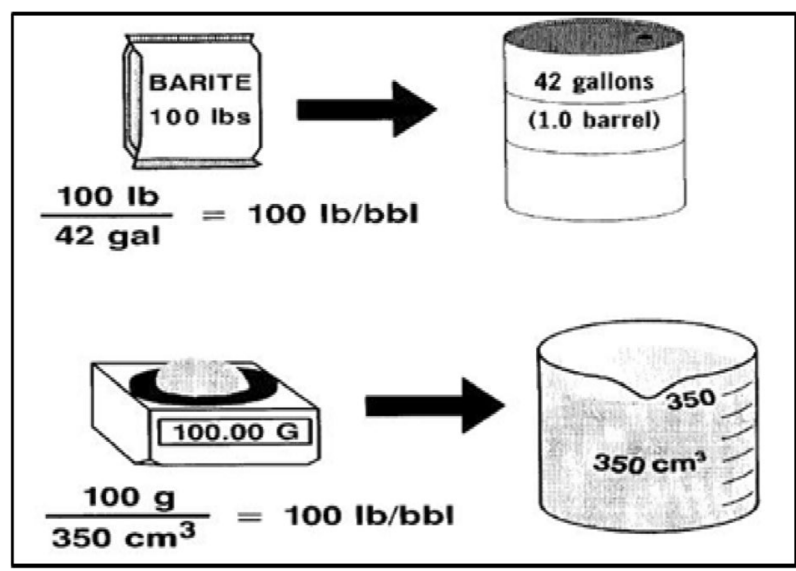

Fig. 8 Pilot testing equivalents (Amoco Production Company 1994)

drilling fluid testing and treating. Pilot testing minimizes the risk of sending a fluid downhole that may be incompatible with the formations to be drilled or that may be ineffective under downhole conditions. Generally, pilot testing is concentrated on the physical properties such as rheology and fluid loss; however, it is important that chemical properties also be evaluated" (Amoco Production Company 1994). Pilot test design requires calculating amounts of materials to put into the test samples. In pilot tests, a gram is equivalent to pound and $350 \mathrm{~cm}^{3}$ is equivalent to one 42 -gal oilfield barrel, or gram is equivalent to kilogram and $1000 \mathrm{~cm}^{3}$ is equivalent to $1 \mathrm{~m}^{3}$; in addition, $1 \mathrm{~kg} / \mathrm{m}^{3}$ is equivalent to $2.85 \mathrm{Ib} / \mathrm{bbl}$. (Basra Oil Company 2007). Figure 8 illustrates pilot testing equivalents.

To ensure an efficient mixture environment to the base fluid and bentonite, make-up water tested for $\mathrm{pH}$ and calcium content $\left(\mathrm{Ca}^{++}\right)$. The test showed $\mathrm{pH}=8.8$ and $\mathrm{Ca}^{++}=50 \mathrm{mg} / \mathrm{l}$; consequently, there was no need to add sodium carbonate $\left(\mathrm{Na}_{2} \mathrm{CO}_{3}\right)$; however, caustic soda $(\mathrm{NaOH})$ was added to increase $\mathrm{pH}$ to 10.5 . The reference mud (RM) sample was spud mud type and prepared using 
only bentonite and $\mathrm{NaOH}$ as conventional chemical additives. The composition of the spud mud sample was $600 \mathrm{cc}$ of water, $0.6 \mathrm{~g}\left(1 \mathrm{~kg} / \mathrm{m}^{3}\right)$ of caustic soda, and $36 \mathrm{~g}(60 \mathrm{~kg} /$ $\mathrm{m}^{3}$ ) of bentonite.

Different concentrations of MPP and PAC-LV ranging between $1 \%$ by weight $(6 \mathrm{~g})$ to a maximum of $4 \%$ by weight ( $24 \mathrm{~g}$ ) were used and added separately to the reference mud, and then, full-set measurements were taken for each concentration to minutely evaluate the influence of concentration variation of MPP and PAC-LV on the properties of the reference mud.

\section{Laboratory measurements}

To evaluate the effect of adding the different concentrations of MPP and PAC-LV on the reference mud, full-set measurements were initially taken for the reference mud, and then, the same measurements were taken after adding MPP and PAC-LV. The tests included rheological properties, filtration characteristics, and mud weight. Rheological properties including plastic viscosity, yield point, initial and final gel strength were conducted using rotary viscometer. The filtration characteristics including fluid loss in cc/30 min and the filter cake thickness were obtained using the standard API filter press at $100 \mathrm{psi}$, while the mud weight was determined using mud balance.

\section{Results}

In this section, the readings that were obtained from the experimental work are presented in details for the reference mud and several concentrations of MPP and PAC-LV, and the aim is to show the effect of MPP and PAC-LV on the reference mud. The results included fluid samples mud weight (MW), plastic viscosity (PV), yield point (YP), gel strength, filtration properties including fluid loss and filter cake thickness, and other physical and chemical properties. In addition, a summary of the experimental results is shown in Tables 1, 2, and 3, which illustrate the laboratory results of the reference fluid (RF), the reference mud plus MPP, and the reference mud plus PAC-LV, respectively.

\section{Discussion and comparative analysis}

Under this section, two parts will be discussed. The first part is to evaluate the effects of adding MPP and PAC-LV to the reference mud sample regarding the physical and chemical properties. The second part will be focused on comparing the performance of MPP and PAC-LV to recognize the magnitude of their influence on the reference mud using various concentrations. In other words, the second part of
Table 1 Reference fluid (RF) sample properties

\begin{tabular}{ll}
\hline Property & Value \\
\hline Mud weight (ppg) & 8.6 \\
$\mathrm{PV}(\mathrm{cp})$ & 7 \\
YP $\left(\mathrm{Ib} / 100 \mathrm{ft}^{2}\right)$ & 11 \\
Initial gel strength $\left(\mathrm{Ib} / 100 \mathrm{ft}^{2}\right)$ & 12 \\
Final gel strength $\left(\mathrm{Ib} / 100 \mathrm{ft}^{2}\right)$ & 17 \\
$\mathrm{pH}$ & 10 \\
Mud resistivity $(\Omega \mathrm{mt})$ & 7 \\
Mud temperature $\left({ }^{\circ} \mathrm{F}\right)$ & 73 \\
Mud NaCl concentration $(\mathrm{ppm})($ nomograph$)$ & 750 \\
7.5 min filtrate $(\mathrm{cc})$ & 6 \\
30 min filtrate $(\mathrm{cc})$ & 12.5 \\
Filter cake thickness $(\mathrm{mm})$ & 3 \\
Filter cake thickness $(\mathrm{mm}) *(32 / 25.4),(1 / 32$ inch) & 3.78 \\
Mud cake resistivity $(\Omega \mathrm{mt})$ & 2.1 \\
Mud cake temperature $\left({ }^{\circ} \mathrm{F}\right)$ & 73 \\
Mud cake NaCl concentration (ppm) (nomograph) & 2700 \\
Ca ${ }^{++}(\mathrm{mg} / \mathrm{l})$ & 40 \\
$\mathrm{NaCl}(\mathrm{mg} / \mathrm{l})(\mathrm{ppm})$ & 182 \\
\hline
\end{tabular}

this section will demonstrate which additive has the highest impact on the properties of the reference mud.

\section{The effect of adding MPP and PAC-LV on mud weight}

Starting with MPP and based on Table 2, it is obvious that MPP had a negligible effect on the mud weight (MW) at $1 \%(6 \mathrm{~g})$ and $2 \%(12 \mathrm{~g})$ concentrations, while a minor impact at 3\% (18 g) and 4\% (24 g) concentrations on MW. The reason behind decreasing the MW was the development of foams in the mud and not MPP itself, and this issue was observable during laboratory work, suggesting using anti-foam additives as pre-treatment or post-treatment to prevent or at least minimize the foaming influence on MW. Plainly, most of the conventional drilling fluid additives, including but not limiting to, CMC, starch, PAC-LV, and salt clay introduce some foam when added to the drilling fluid base. The problem with foam presence is that it will slightly reduce the mud weight (density) of the drilling fluid due to the entrapped bubbles. It can also reduce the tanks volume capacity by raising the liquid level above its actual non-foamed level. To eliminate the problems of foam generation in the drilling fluid, environmentally friendly defoamers (anti-foamers) can be used. There are some environmentally accepted silicon products that are used in water treatment facilities to eliminate foams. Another suggestion is to use physical degassing/ defoaming pumps which are used as standard equipment on the mud system during the drilling phase. Using the pumps will eliminate the needs for using any defoaming

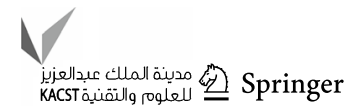


Table 2 The results of adding various concentrations of MPP on the properties of reference fluid

\begin{tabular}{lllll}
\hline Property & $1 \%$ MPP & $2 \%$ MPP & $3 \%$ MPP & $4 \%$ MPP \\
\hline Mud weight (ppg) & 8.4 & 8.2 & 8 & 8 \\
PV $(\mathrm{cp})$ & 14 & 24 & 38 & 63 \\
YP $\left(\mathrm{Ib} / 100 \mathrm{ft}^{2}\right)$ & 14 & 17 & 33 & 57 \\
Initial gel strength $\left(\mathrm{Ib} / 100 \mathrm{ft}^{2}\right)$ & 10 & 10 & 12 & 24 \\
Final gel strength $\left(\mathrm{Ib} / 100 \mathrm{ft}^{2}\right)$ & 14 & 14 & 17 & 28 \\
$\mathrm{pH}$ & 8 & 7.7 & 7 & 6.8 \\
Mud resistivity $(\Omega \mathrm{mt})$ & 5.8 & 5.2 & 5 & 4.8 \\
Mud temperature $\left({ }^{\circ} \mathrm{F}\right)$ & 76 & 76 & 76 & 74 \\
Mud NaCl concentration $(\mathrm{ppm})($ nomograph) & 900 & 1000 & 1050 & 1100 \\
7.5 min filtrate $(\mathrm{cc})$ & 3.5 & 2.75 & 2 & 1.75 \\
30 min filtrate $(\mathrm{cc})$ & 7 & 6 & 4.5 & 4 \\
Filter cake thickness $(\mathrm{mm})$ & 1.6 & 1.4 & 1.35 & 1.35 \\
Filter cake thickness $(\mathrm{mm}) *(32 / 25.4),(1 / 32$ inch) & 2 & 1.76 & 1.7 & 1.7 \\
$\mathrm{Mud} \mathrm{cake} \mathrm{resistivity}(\Omega \mathrm{mt})$ & 1.3 & 0.85 & 0.77 & 0.77 \\
$\mathrm{Mud}$ cake temperature $\left({ }^{\circ} \mathrm{F}\right)$ & 72 & 74 & 74 & 74 \\
$\mathrm{Mud}$ cake NaCl concentration $(\mathrm{ppm})($ nomograph) & 4500 & 7000 & 7500 & 7500 \\
$\mathrm{Ca}{ }^{++}(\mathrm{mg} / \mathrm{l})$ & 4 & 4 & 4 & 4 \\
$\mathrm{NaCl}(\mathrm{mg} / \mathrm{l})(\mathrm{ppm})$ & 247.5 & 330 & 330 & 330 \\
\hline
\end{tabular}

Table 3 The results of adding various concentrations of PAC-LV on the properties of reference fluid

\begin{tabular}{|c|c|c|c|c|}
\hline Property & $1 \%$ PAC-LV & $2 \%$ PAC-LV & $3 \%$ PAC-LV & 4\% PAC-LV \\
\hline Mud weight (ppg) & 8.6 & 8.4 & 8.35 & 8.35 \\
\hline PV (cp) & 25 & 52 & 69 & None \\
\hline $\mathrm{YP}\left(\mathrm{Ib} / 100 \mathrm{ft}^{2}\right)$ & 26 & 68 & 109 & None \\
\hline Initial gel strength $\left(\mathrm{Ib} / 100 \mathrm{ft}^{2}\right)$ & 15 & 37 & 55 & 110 \\
\hline Final gel strength $\left(\mathrm{Ib} / 100 \mathrm{ft}^{2}\right)$ & 36 & 68 & 99 & 185 \\
\hline $\mathrm{pH}$ & 9.7 & 9.3 & 9.3 & 9.2 \\
\hline Mud resistivity ( $\Omega \mathrm{mt})$ & 5.5 & 4 & 3 & 2.2 \\
\hline Mud temperature $\left({ }^{\circ} \mathrm{F}\right)$ & 74 & 76 & 82 & 84 \\
\hline Mud $\mathrm{NaCl}$ concentration (ppm) (nomograph) & 950 & 1300 & 1600 & 2200 \\
\hline 7.5 min filtrate $(\mathrm{cc})$ & 3 & 2.5 & 2 & 1.75 \\
\hline 30 min filtrate (cc) & 6 & 5 & 4.5 & 3.75 \\
\hline Filter cake thickness (mm) & 1.9 & 2.2 & 2.3 & 2.5 \\
\hline Filter cake thickness, (1/32 inch) & 2.4 & 2.8 & 2.9 & 3.14 \\
\hline Mud cake resistivity $(\Omega \mathrm{mt})$ & 0.85 & 0.71 & 0.4 & 0.32 \\
\hline Mud cake temperature $\left({ }^{\circ} \mathrm{F}\right)$ & 74 & 76 & 84 & 78 \\
\hline Mud cake $\mathrm{NaCl}$ concentration (ppm) (nomograph) & 6600 & 8000 & 13,000 & 18,500 \\
\hline $\mathrm{Ca}^{++}(\mathrm{mg} / \mathrm{l})$ & 8 & 12 & 12 & 12 \\
\hline $\mathrm{NaCl}(\mathrm{mg} / \mathrm{l})(\mathrm{ppm})$ & 330 & 450 & 495 & 660 \\
\hline
\end{tabular}

chemical agent. Finally, based on laboratory findings, the MPP has shown minimum foaming criteria, and in largescale applications, if the mud weight will be affected due to the foam, mud weight weighing agents such as barite can be used to increase the mud weight to the desired control density. Thus, there is no concern that MPP has a side effect on MW, and all the above solutions will maintain the main purpose of providing environmentally friendly drilling fluid system. On the other hand, it is clearly seen that PAC-LV at $1 \%(6 \mathrm{~g})$ had no effect on MW and it had a negligible effect on MW at 2\% (12 g), 3\% (18 g), and $4 \%$ ( $24 \mathrm{~g}$ ) concentrations, but a little decrease in the MW was noticed due to the foaming impact. In conclusion, it can be said that both MPP and PAC-LV approximately had the same performance and impact on the MW as shown in Fig. 9. 
Fig. 9 The effect of MPP and PAC-LV on mud weight

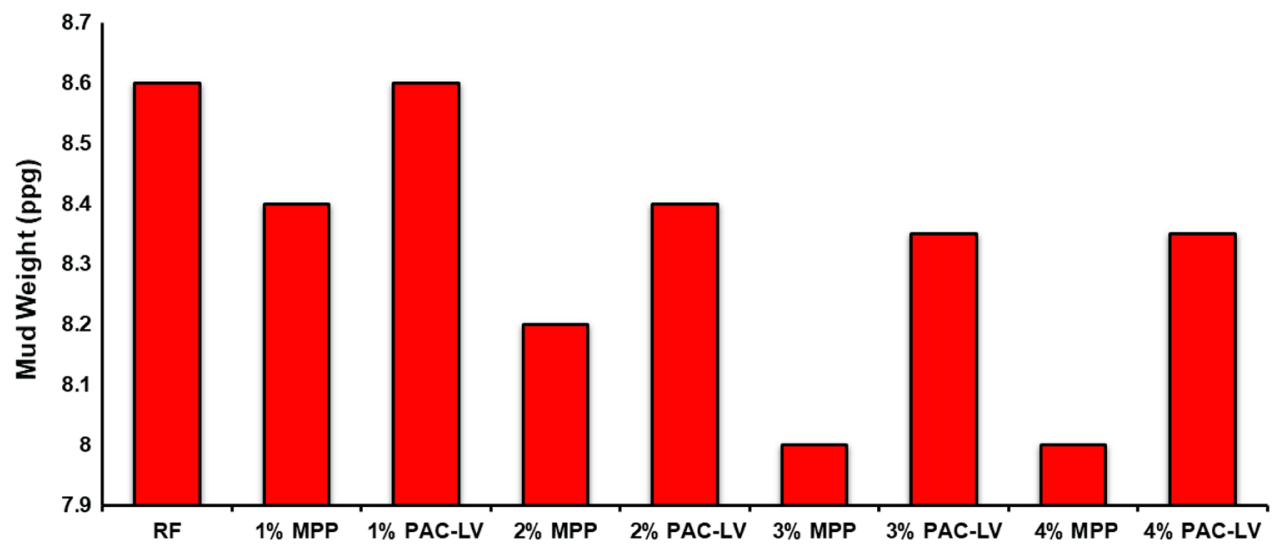

\section{The effect of adding MPP and PAC-LV on rheological properties}

For the rheological properties, MPP significantly resulted in increasing PV and YP, especially at 3\% and $4 \%$ concentrations. These results suggest the MPP applicability to be utilized as viscosity modifier at $1 \%$ and $2 \%$ concentrations during the normal drilling operations, while it can be used to control the partial losses at $3 \%$ and $4 \%$ concentrations due to the high marsh funnel viscosity $(\approx 100 \mathrm{~s})$. In addition, MPP generated an excellent behavior for the gel strength since the difference between the initial and final gel strength did not exceed $5\left(\mathrm{Ib} / 100 \mathrm{ft}^{2}\right)$, which will be reflected positively on the drilling operations, particularly during pump-off conditions (Basra Oil Company 2007).

For PAC-LV, the results showed that PAC-LV extremely increased PV and YP, especially at $2 \%$ and $3 \%$ concentrations, while viscometer could not read the rotation speed $\left(\theta_{600}\right)$ at $4 \%$ concentration of PAC-LV since the reading was higher than $330 \mathrm{rpm}$. For this reason, there were no values for PV and $\mathrm{YP}$ at $4 \%$ concentration of PAC-LV as shown in Table 3. Regarding the gel strength, PAC-LV had a negative effect on both the initial and final gel strengths, and the difference between them was much higher than $10 \mathrm{Ib} / 100 \mathrm{ft}^{2}$. Thus, extra pressure will be needed to break the gel strength during switching from pump-off to pump-on conditions, which in return will affect the pump efficiency and may cause induce fractures in weak formations. In addition, PAC-LV at $3 \%$ and $4 \%$ concentrations cannot be used to stop partial losses as a high viscosity patch since the mud pump will be damaged (Basra Oil Company 2007).

It has long been known that PAC-LV is an excellent chemical additive for the drilling mud, and it has been practically applied in different wells worldwide. However, the main reason behind the extravagant increasing in rheological properties due to adding PAC-LV to the reference mud was the high concentration. In the field, $\left(1.2-1.8 \mathrm{~kg} / \mathrm{m}^{3}\right)$ of PAC-LV is usually added to the drilling fluid to achieve the required aims, which is equivalent to $(1.2-1.8 \mathrm{~g} / 1000 \mathrm{cc})$ for the laboratory purposes. While for this experimental work, $6 \mathrm{~g} / 600 \mathrm{cc}, 12 \mathrm{~g} / 600 \mathrm{cc}$, $18 \mathrm{~g} / 600 \mathrm{cc}$, and $24 \mathrm{~g} / 600 \mathrm{cc}$ of PAC-LV were used and added to the reference mud to have the same concentration variation with MPP. For this reason, the rheological properties were extremely maximized after adding PACLV concentrations as shown in Fig. 10.

\section{The effect of adding MPP and PAC-LV on filtration characteristics}

Fluid filtration loss was measured at 100 psi utilizing standard API filter press to understand the effectiveness of MPP as an environmentally friendly filtration control agent. The fluid loss was measured at $7.5 \mathrm{~min}$ and $30 \mathrm{~min}$; an excellent enhancement in the fluid loss was observed, particularly at $3 \%$ and $4 \%$ concentrations as shown in Fig. 11. In addition, the filter cake thickness was majorly minimized as shown in Fig. 11. Regarding PAC-LV, laboratory results showed that PAC-LV had almost the same effect on the seepage loss as shown in Fig. 11. However, MPP showed better improvement in the filter cake as compared to PAC-LV performance as shown in Fig. 11. This suggests the feasibility of using MPP to enhance the filter cake before securing the hole with casing string to avoid any potential of mechanical stuck pipe due to thick mud cake.

It is crucial to mention that a simple food processor has been used to grind the dried mandarin peels. MPP was not as fine as PAC-LV. As known, finer particles help to reduce filtration loss efficiently. Hence, using an excellent grinder to grind the MPP into very fine particles would provide better performance in controlling the filtration. Therefore, it is desirable to the use of a more powerful grinder to grind mandarin peels to $105-125 \mu \mathrm{m}$ (140 US Mesh size-120 US Mesh size) which is considered very fine and close to the size of PAC-LV alternative chemical product for the purpose of better future comparison.

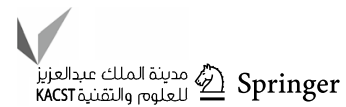




\section{The effect of adding MPP and PAC-LV on alkalinity}

The results clarified that MPP had the applicability to be utilized as $\mathrm{pH}$ reducer at high concentrations, which suggest its feasibility in being used as $\mathrm{pH}$ control agents, especially when drilling through cement since it can reduce the $\mathrm{pH}$ effectively and precipitate the calcium content as well. Figure 12 shows the effect of adding MPP on alkalinity, while PAC-LV had much less influence on $\mathrm{pH}$ when compared to MPP as shown in Fig. 12.
Fig. 10 The effect of MPP and PAC-LV rheological properties
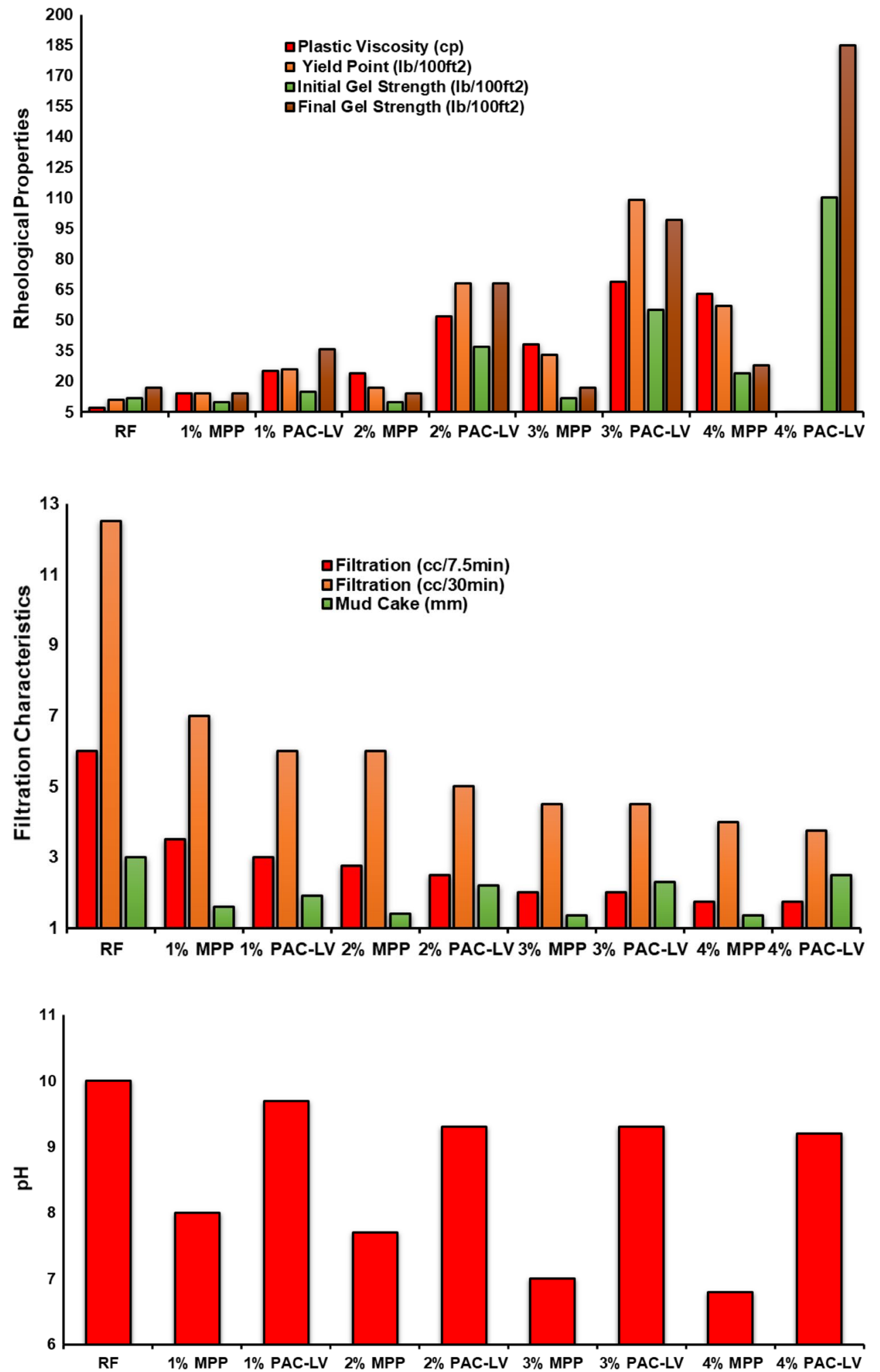

Fig. 12 The effect of MPP and PAC-LV on $\mathrm{pH}$
Fig. 11 The effect of MPP and PAC-LV filtration characteristics 


\section{The effect of adding MPP and PAC-LV on salinity and calcium content}

The laboratory outcomes demonstrated that MPP had less effect on the salinity as compared to PAC-LV in terms of increasing $\mathrm{NaCl}$, while MPP showed the potential to precipitate the calcium content $\left(\mathrm{Ca}^{++}\right)$better than PAC-LV. Consequently, it is practically applicable to examine the feasibility of MPP in penetrating the cement since it showed the possibility to reduce $\mathrm{pH}$ and precipitate $\mathrm{Ca}^{++}$. Figures 13 and 14 illustrate the effect of MPP and PAC-LV on mud $\mathrm{NaCl}$ concentration, mud cake $\mathrm{NaCl}$ concentration, mud filtrate $\mathrm{NaCl}$ concentration, and the calcium content, respectively.

\section{Economic evaluation, environmental, health, and safety considerations}

It has been long known that drilling mud has a pivotal role in the drilling operations, and it has several important functions in rotary drilling operations. For the drilling fluid to obtain all the required properties, a drilling fluid is a complex fluid mixture with a base fluid like water or oil with different materials and chemicals added based on the design process. The design process of mud is made so that the mud gets specific properties. However, there are three main concerns for the conventional chemical additives that are used to formulate the drilling mud, and these concerns are cost, environmental regulations, health, and safety considerations.

When it comes to drilling operations, several factors play a part in the total drilling cost. One of these factors is the cost of drilling fluid. When drilling a well, a drilling fluid is needed to complete the well and it might seem like a straightforward process, but it is not as it requires careful planning economically and technically. The drilling operation is an expensive process, and drilling mud is a tangible part of this expense. Drilling mud cost can be as high as a million dollars to as low as roughly half a million dollars as shown in Fig. 15. This figure shows real cost data of drilling fluid from the total cost of the drilling operations. This is just an example from some drilled wells in the South Rumaila field to provide a better picture of drilling mud cost, and
Fig. 13 The effect of MPP and PAC-LV salinity

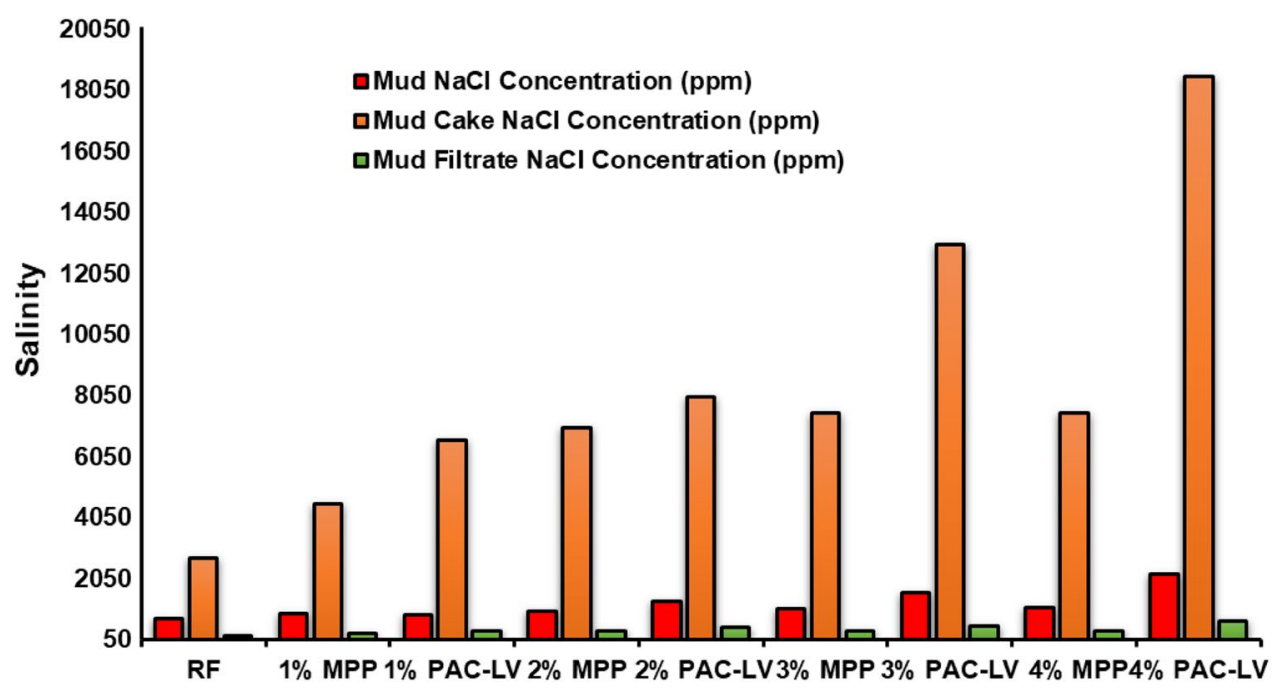

Fig. 14 The effect of MPP and PAC-LV on calcium content

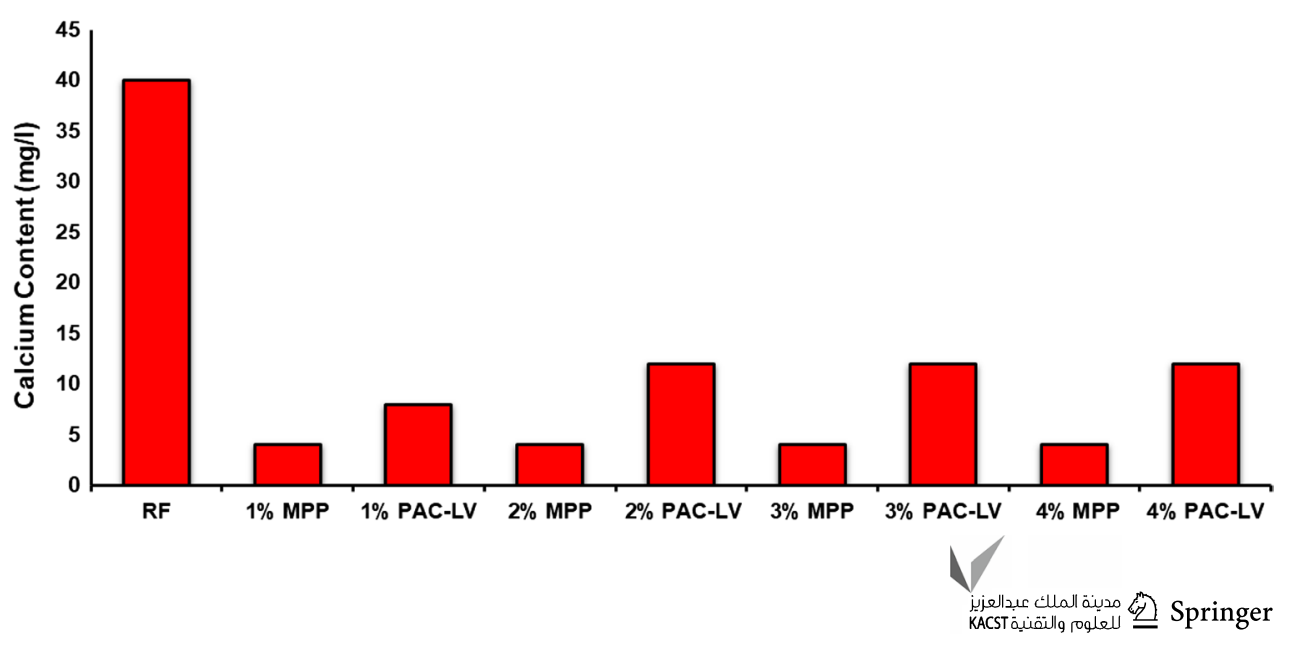


this field from Iraq is provided to compare the prices of total drilling cost with the drilling mud cost. These prices take about one-tenth of the total cost of drilling operations. Therefore, when using food waste products additives, the expenses will be decreased, and the total drilling cost would be cheaper than applying conventional drilling mud additives (Basra Oil Company 2016).

Hence, the ultimate objective of this paper is to present new alternatives or supportive materials for drilling fluid additives, which are food waste products that are discarded by people. The food waste products are available everywhere and are easily accessible. Thus, they are good candidates for further investigation. The price for collecting and preparing the food waste products is much cheaper when comparing it with the conventional chemical additives.

Food loss and waste products account for about $8.2 \%$ of the greenhouse gas emissions as shown in Fig. 16, and it can be utilized for better uses such as drilling fluid additives. It is also generally safer to handle food waste in comparison with chemical additives as some chemical additives have hazards that require proper equipment and safety to be handled.

Additionally, when it comes to handling drilling fluid additives, it is important to consider the effects of health, safety, and environment. Drilling fluid should be handled carefully to avoid unwanted problems. That is why when handling drilling fluid, it is important for the personnel to wear personal protective equipment (PPE) to avoid health and safety problems. By wearing the personal protective equipment, rig personnel can ensure safety when handling drilling fluid that can cause severe health problems due to the toxicity of the chemical materials (Basra Oil Company 2007).

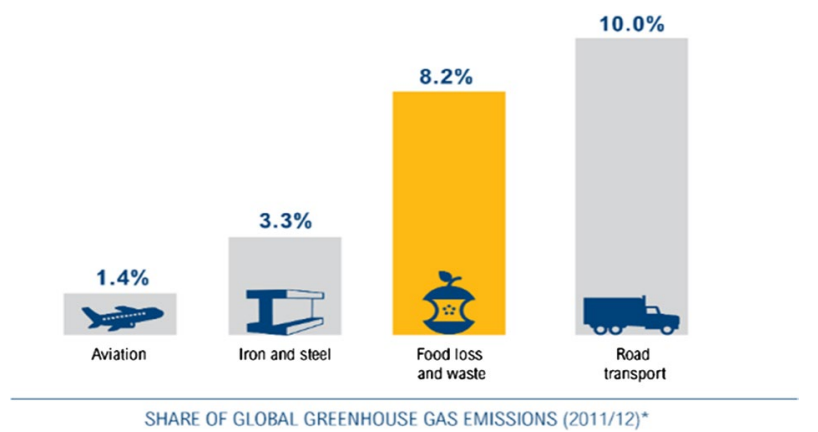

Fig. 16 Greenhouse emission from food loss and waste (FAO 2015)

\section{Conclusions}

By studying the effects of adding several concentrations of MPP to the drilling fluid, different findings were obtained from this work. These findings are based on analyzing the measurements of mud weight, rheological properties, filtration characteristics, the alkalinity, and salinity of the drilling fluid. The main conclusions are summarized below:

- The mud weight was slightly affected by adding MPP, and this effect was due to the development of foams in the mud. Thus, suggesting the need for adding anti-foam additive as pre-treatment or post-treatment to inhibit or at least reduce the foaming impact on MW. Similarly, the same effect on MW was faced due to adding PAC-LV and for the same reason.

- The results showed that MPP significantly increased PV and YP of the drilling mud, especially at 3\% and 4\% concentrations. Hence, MPP showed the capability to be used as viscosity modifier at $1 \%$ and $2 \%$ concentrations
Fig. 15 The cost of the drilling fluid from the total cost of the drilling operations

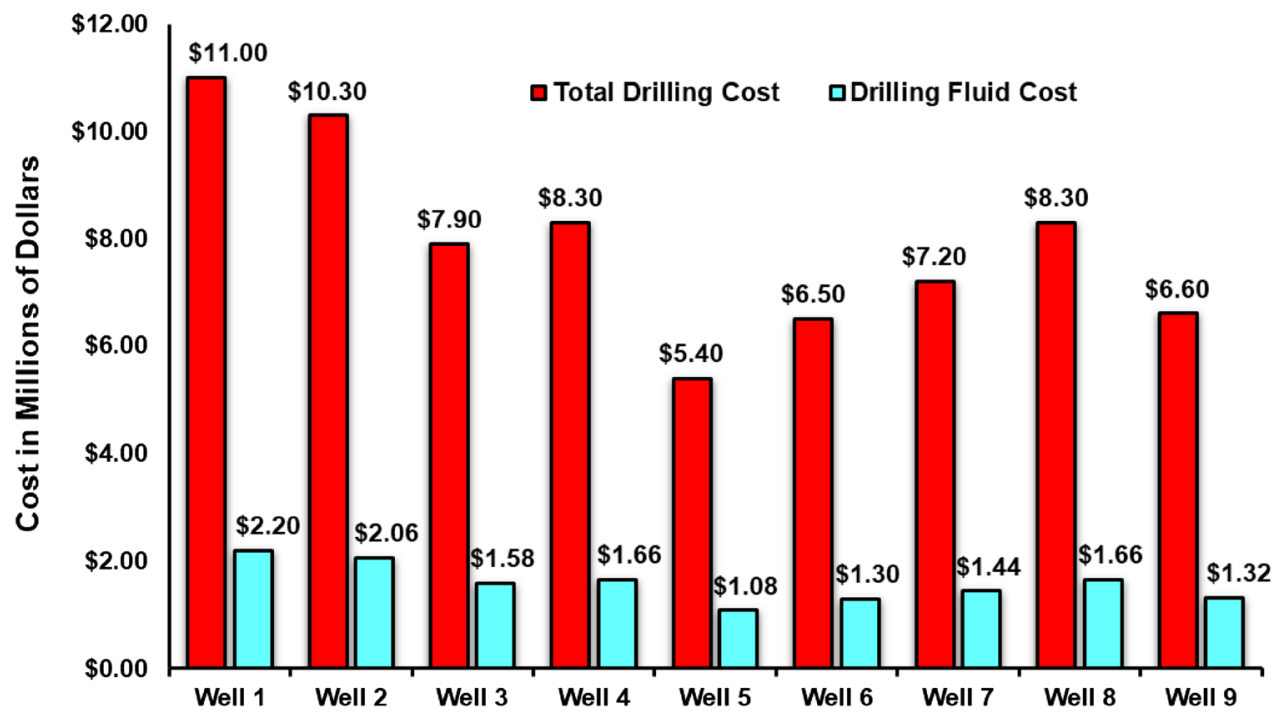


during the normal drilling operations and to combat the partial losses at higher concentrations. Additionally, an excellent behavior for the gel strength was presented, because the difference between the initial and final gel strengths was practically desirable and did not exceed $5\left(\mathrm{Ib} / 100 \mathrm{ft}^{2}\right)$.

- A tremendous increase in PV and YP was encountered due to PAC-LV additives, particularly at $2 \%$ and $3 \%$ concentrations; in addition, there was no reading for the rotation speed $\left(\theta_{600}\right)$ at $4 \%$ due to the extreme viscosity. Moreover, PAC-LV presented a bad performance for the gel strength because the difference between the initial and final gel strength was greater than $10\left(\mathrm{Ib} / 100 \mathrm{ft}^{2}\right)$. Consequently, extra pressure will be applied to break the gel strength during switching from pump-off to pump-on conditions.

- MPP tangibly improved the filtration characteristics by reducing the fluid loss and the mud cake thickness, especially at $3 \%$ and $4 \%$ concentrations, suggesting its applicability to be used as fluid loss control agents. In addition, due to excellent improvement in minimizing the filter cake as compared to the base mud, this shows the feasibility of using MPP to enhance the filter cake before securing the hole with casing string to avoid any potential of mechanical stuck pipe due to thick mud cake. In the same vein, PAC-LV results approximately showed the same enhancement in reducing the seepage loss; however, PAC-LV was less efficient than MPP regarding the mud cake thickness.

- Based on the laboratory results for MPP additive, it can be suggested to be used as $\mathrm{pH}$ reducer, particularly at high concentrations, and especially when drilling through cement, since it can reduce the $\mathrm{pH}$ effectively and precipitate the calcium content, while PAC-LV had much less influence on $\mathrm{pH}$ when compared to MPP.

- PAC-LV additives increased $\mathrm{NaCl}$ concentrations more than MPP additives.

- It is important to point out that the grinding of MPP was in a very simple way, and as known, having finer particles help to reduce the filtration loss. Hence, better performance in the filtration characteristics is expected if more advanced grinding technique is used to grind MPP. This was the main reason, which showed PAC-LV additives had a slightly better performance in minimizing the fluid loss as compared to MPP additives.

- This work proves the importance of following the tendency of expanding biodegradable environmentally friendly drilling mud additives to participate toward reducing the effect on the environment and personal safety as well as the total cost of drilling operations and drilling waste handling.

Open Access This article is distributed under the terms of the Creative Commons Attribution 4.0 International License (http://creat ivecommons.org/licenses/by/4.0/), which permits unrestricted use, distribution, and reproduction in any medium, provided you give appropriate credit to the original author(s) and the source, provide a link to the Creative Commons license, and indicate if changes were made.

\section{References}

Adebowale A, Raji J (2015) Local content supplements as an alternative to imported corrosion control additives for drilling mud treatment (a case study of the use of burnt plantain and banana peels. In: Proceedings of the international academic conference for sub-Sahara African transformation and development, vol 3

Al-Hameedi ATT, Alkinani HH, Dunn-Norman S, Albazzaz HW, Alkhamis MM (2019a) Insights into eco-friendly and conventional drilling additives: applications, cost analysis, health, safety, and environmental considerations. Society of Petroleum Engineers. https ://doi.org/10.2118/195398-ms

Al-Hameedi ATT, Alkinani HH, Dunn-Norman S, Alashwak NA, Alshammari AF, Alkhamis MM, Alsaba MT (2019b) Environmental friendly drilling fluid additives: can food waste products be used as thinners and fluid loss control agents for drilling fluid?. Society of Petroleum Engineers. https://doi.org/10.2118/195410-ms

Amanullash M (2007) Screening and evaluation of some environmentfriendly mud additives to use in water-based drilling muds. Society of Petroleum Engineers. https://doi.org/10.2118/98054-ms

Amoco Production Company (1994) Drilling fluids manual

Balestrini A, Maas A, Seheult M, Morton EK (2009) Advances in API/ISO standard grade purified poly-anionic cellulose (PAC) and drilling grade xanthan gum (XG) test procedure and specifications definition. Society of Petroleum Engineers. https://doi. org/10.2118/119973-ms

Basra Oil Company. Various daily reports, final reports, and tests for 2006, 2007, 2008, 2009 and 2010, 2012, 2013, 2016. Several drilled wells, Basra Oil Fields, Iraq

FAO-Food waste worsens GHG emissions (2015) Retrieved from https ://climatenewsnetwork.net/food-waste-worsens-ghg-emissions-fao/

Gray GR, Darley HCH, Rogers WF (1980) Composition and properties of oil well drilling fluids, 4th edn. Gulf Publishing, Houston, TX

Halliburton (2018) Products data sheet. http://www.halliburton.com/. Accessed 24 Feb 2019

Iheagwara $\mathrm{O}$ (2015) Comparative analysis of the use of banana peels and $\mathrm{NaOH}$ in $\mathrm{Ph}$ control in Nigerian clays. J Niger Assoc Math Phys 30:197-202

Iranwan S, Azmi A, Saaid M (2009) Corn cobs and sugar cane waste as viscosifier in drilling fluid. Pertanika J Sci Technol 17:173-181

Nmegbu J, Bekee BA (2014) Evaluation of corn cob cellulose and its suitability for drilling mud formulation. J Eng Res Appl 4:112-117

Nyeche W, Nmegbu J, Ifeoma P (2015) Drilling mud formulation using potato starch (Ipomoea batatas). J Eng Res Appl 5:48-54

Okon AN, Udoh FD, Bassey PG (2014) Evaluation of rice husk as fluid loss control additive in water-based drilling mud. Society of Petroleum Engineers. https://doi.org/10.2118/172379-ms

Okorie MO (2009) Modification of drilling fluid PH with local additives (ash of burnt palm head sponge[BPHSP] and a rich potash mineral known as Trona. Pet Technol Dev J 1:1-16 ISSN: 1595-9104

Omotioma M, Ejikeme PCN, Mbah GO (2014) Comparative analysis of the effects of cashew and mango extracts on the rheological properties of water based mud. J Eng Res Appl 4:56-61

Thomas DC (1982) Thermal stability of starch- and carboxymethyl cellulose-based polymers used in drilling fluids. Society of Petroleum Engineers. https://doi.org/10.2118/8463-pa

Publisher's Note Springer Nature remains neutral with regard to jurisdictional claims in published maps and institutional affiliations. 